\title{
International patent applications and innovation in South Africa
}

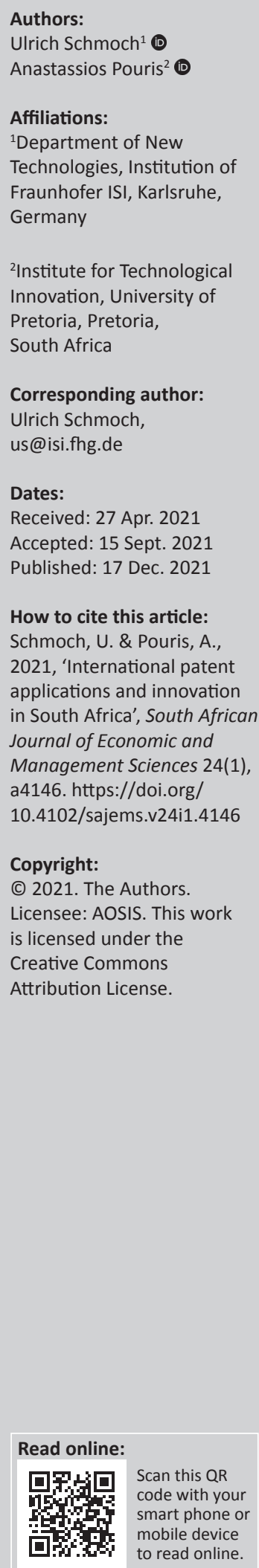

Background: Experts recommend support to patents for stimulating innovation. Also, the South African government supports patents, in particular, international patents. In this paper it is examined how this strategy can be designed to successfully trigger economic progress.

Aim: The present South African activities in patents are investigated in this paper and areas identified where an intensification of patenting looks promising for economic progress.

Setting: The patent activities since 1985 are analysed and compared to the annual exportimport balance from 2009 to 2018, in order to identify starting points for improving economic structures. The data are linked to current suggestions to the National Advisory Council on Innovation (NACI) for future technologies.

Methods: The analysis of patents is performed, using the international patent database PATSTAT, as well as the analysis of the export-import balance at the WITS database of the World Bank.

Results: The patent analysis reveals a low level of South African domestic patents, with a focus on less complex goods and a stagnation period of 35 years. The data on the export import balance show negative figures for consumer goods and even more so for capital goods.

Conclusion: Economic progress can be accelerated by stimulating patent and economic activities to produce more complex consumer and capital goods. However, it may be necessary to focus on certain areas at the beginning in order to achieve a sufficient critical mass of competence and international competitiveness. In any case, the support of patents is only successful when it is closely linked to a strategy regarding technology.

Keywords: international patents; domestic patents; export-import balance; future technologies; technology focus; South Africa.

\section{Introduction}

In the discussion on economic growth in developing and threshold countries, experts broadly agree that innovation plays a key role in success (eds. Lundvall et al. 2011). When supporting innovation, intellectual property rights, in particular patents, are considered an important tool (Chen \& Puttitanun 2005). In the global environment of innovation, international patents according to the Patent Cooperation Treaty - the so called PCT applications - were introduced for facilitating patenting in foreign countries. In order to stimulate innovation, various countries, such as Japan or China, actively support PCT patents (Boeing \& Mueller 2015). In this context, the South African government also supports PCT patents (NIPMO 2019). In this paper, we shall examine whether the approach is a realistic tool for stimulating innovation.

\section{International patent applications}

For understanding the link between PCT patents and innovation, it is necessary to explain what international patents are, what procedures are followed in their application and what the advantages and disadvantages are.

The Patent Cooperation Treaty (PCT) is an international treaty accepted in 1970. It introduced the international application, which provides a unified international procedure for filing a patent. The application is made at a Receiving Office (RO) in one language. The next step is a search, performed by an International Search Authority (ISA), resulting in a search report with a stated opinion regarding the patentability of the invention, which is the subject of the application. It is followed, optionally, by a preliminary examination performed by an International Preliminary Examining Authority (IPEA). The ROs, ISAs and IPEAs are selected existing patent offices, for 
example, the United States Patent and Trademark Office (USPTO) or the European Patent Office (EPO), working on behalf of the World Intellectual Property Organisation (WIPO). In the final step, the inventor/applicant has to decide whether to pursue the application and in which countries to file for patent protection. The WIPO has 193 member states. Another option is to apply at the European Patent Office (EPO) as well, that is, the so-called Euro-PCT application. This international application has a number of advantages. In particular:

- The applicant can submit valid applications designated for foreign countries shortly before the end of the priority year, as a translation into a foreign language and nominating corresponding patent attorneys in the designated states are not necessary at this point in time, while these are required in the standard procedure without PCT.

- The applicant receives valid information on the patentability of the application, through the reports of the ISAs and IPEAs, before making a decision about costintensive applications in foreign countries.

- The international phase ends 30 months after the priority date and, therefore, the applicant has to make the decision concerning applications in foreign countries much later than by the end of the priority year. Two and a half years after the priority application, more information should be available on whether the invention will be successful in the market and this could justify the cost of patent applications in foreign countries.

To conclude, PCT applications are generally made if the aim is to apply at several foreign patent offices. However, the search report and the preliminary examination offer the option to decide not to transfer the application to several national offices. Thus, an international application generally implies applications in several countries; however, a certain share of PCT applications is not transferred to foreign countries.
If a patent application in only one external country is intended, the detour through a PCT application is not rational, as it implies additional costs.

\section{Patent structures in South Africa}

For understanding the patent situation in South Africa, it is useful to look at patenting trends. To investigate the patent applications by South Africans here, we used and compared different databases, in particular: INPADOC - a database of the European Patent Office (EPO) which comprises patent documents of more than 50 patent offices worldwide; World Patens Index (WPI) - a database of the provider Derwent also with patent documents of more than 50 patent offices, organised according to patent families; and PATSTAT - a relational database of the EPO for worldwide patent searches. Due to the different structures of the databases, the results differ a little bit, though not much.

In Figure 1, the situation since 1985, that is, since the apartheid period, is shown. In the case of PCT applications by South African inventors, a substantial increase is observed in the 1990s. This is linked to a worldwide acceptance of the PCT system during this period, due to a decisive improvement in the administrative application procedures. The PCT application had reached a peak in 1998, and had been decreasing since.

Other important channels of applications in foreign countries are applications at the EPO, as well as at the United States Trademark and Patent Office (USPTO). The USPTO applications had increased since 1994 at the end of the apartheid regime (Figure 1). The numbers increased steadily until 2013 and then sharply decreased. In 2017 and 2018, the main reason for the decrease was that the majority of the US applications had been filed through the PCT system and, due to the late transfer after two and a half years to other offices, the PCT applications, with destination USPTO, had not yet appeared on the US system. Also, the EPO applications exhibited a sharp decline in 2017 and 2018, as the majority are

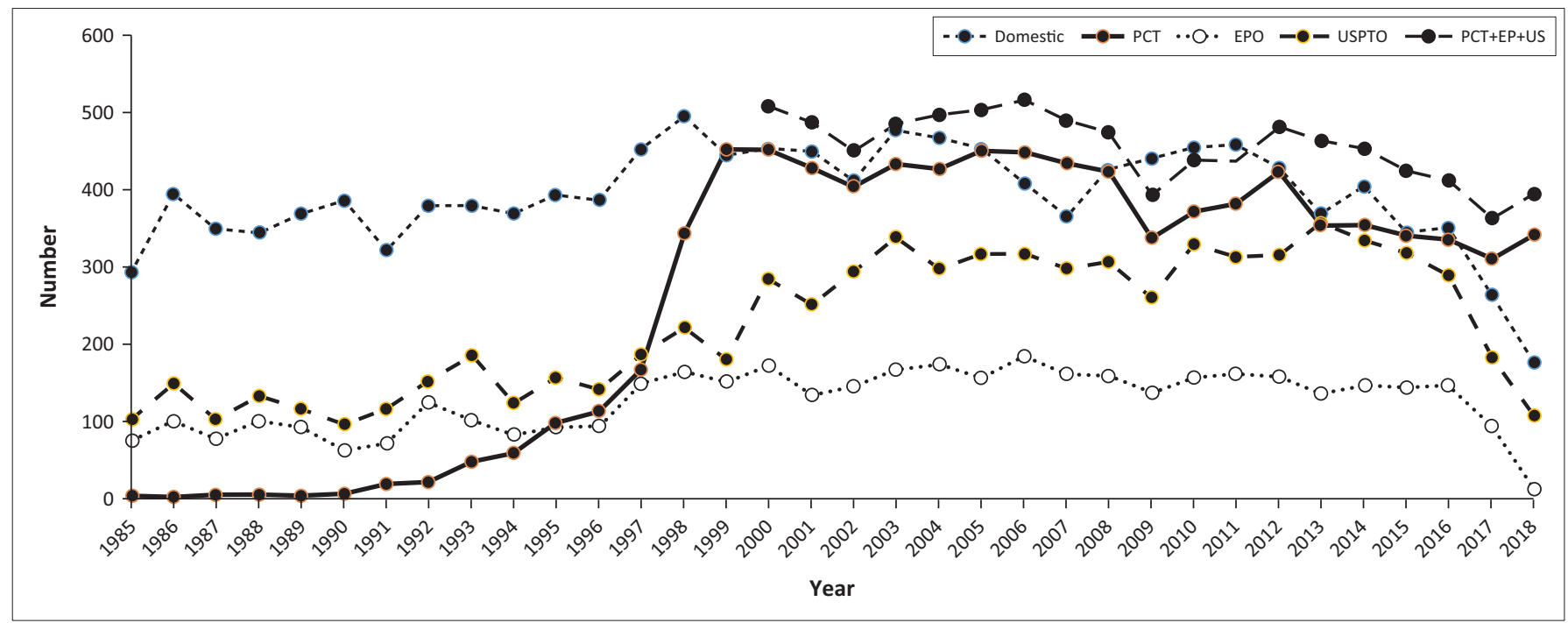

PCT, Patent Cooperation Treaty; EPO, European Patent Office; USPTO, United States Patent and Trademark Office.

FIGURE 1: Patent applications of South Africans in different patent systems. 
Euro-PCT applications. When the patent families with US, EP or PCT applications are counted, the number is only slightly higher than the PCT applications, as the majority of applications in foreign countries was filed through the PCT system.

Interpretation of the domestic applications at the South African Companies and Intellectual Property Commission (CIPC) is very difficult (Pouris \& Pouris 2011). For many years, the applications at the CIPC was not documented electronically; then for some years this documentation was realised by INPADOC, and discontinued again after a while. In 2009, the World Intellectual Property Organisation (WIPO) took the initiative to digitalise South African applications (http://www.rci.uct.ac.za/news/new-south-african-onlinepatents-database-now-available-wipo). However, coverage still seems to be incomplete. In general, the number of domestic applications was substantially higher than that of foreign applications. In Figure 1, the domestic applications and the PCT applications are almost on the same level. This makes the decrease in the number of domestic applications in 2018 incomprehensible. Most probably, a considerable number of applications were registered too late.

Considering the applications of foreigners at the CIPC, the development was quite volatile over time. In particular, the strong slumps in 1999 and 2000, and again in 2016 and 2017 were striking (Figure 2). The most probable explanation is incomplete registrations on the databases. According to information from CIPC, the total number of patent applications in South Africa was 7544 in 2017, and 6915 in 2018. This is more than the numbers registered on the databases. Assuming that about $15 \%$ of the applications had been withdrawn before their publication 18 months later, a level of about 6000 published applications per year would have been realistic. According to the databases, this was achieved between 2001 and 2014. In more recent years, the electronic registration was obviously incomplete.
The CIPC states that about $10 \%$ of all applications are domestic. In the available electronic statistics this share is about $7 \%$. Again this is an indication that the coverage of the electronic databases is incomplete, in particular for domestic applications.

Against the background of this disappointing situation, it is less meaningful to compare the technological structures of the domestic and PCT applications from South Africans with those of foreign applicants in this country. Figure 3 shows the profile of specialisation in South African PCT applications. For this purpose, the specialisation index Revealed Patent Advantage (RPA) is calculated as follows:

$\operatorname{RPA}_{\mathrm{kj}}=100 *\left(\ln \left[\left(\mathrm{P}_{\mathrm{kj}} / \sum_{\mathrm{j}} \mathrm{P}_{\mathrm{kj}}\right) /\left(\sum \mathrm{kP}_{\mathrm{kj}} / \sum_{\mathrm{kj}} \mathrm{P}_{\mathrm{kj}}\right)\right]\right)$

[Eqn 1]

Therein, the index $\mathrm{k}$ stands for the country and the index $\mathrm{j}$ for the technology. Positive values represent an above-average specialisation, negative ones below-average specialisation; the neutral value is 0 . As reference, the international distribution of technologies in transnational patents (Frietsch \& Schmoch 2010) is taken. Thus, positive values indicate a specialisation in the specific technology above the international average. The range of technologies is defined according to a classification of the WIPO, covering all fields of technology (Schmoch 2008). The results for the PCT statistics are realistic, because the electronic registrations of their applications are correct.

In the profile of the RPA (Eqn 1) for the PCT applications in South Africa, all fields in electrical engineering, semiconductors and information technology show specialisation below average, with the exception of, mainly, IT methods. These are software-related patents in the context of commercial applications, such as administration, finance, logistics etc. (Figure 3). Further positive specialisations refer to technologies linked to general consumption, for example: food chemistry, chemical engineering, consumer goods or civil engineering.

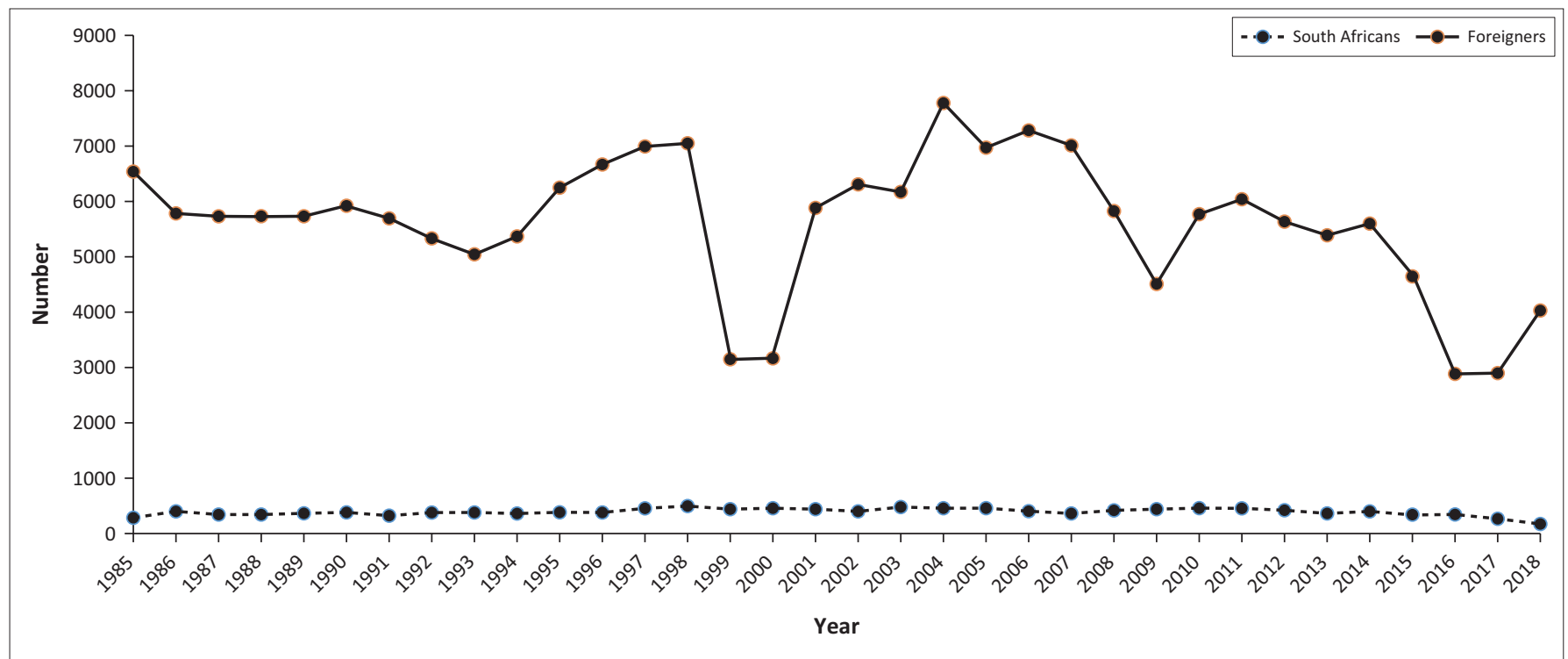

FIGURE 2: Patent applications at the Companies and Intellectual Property Commission. 


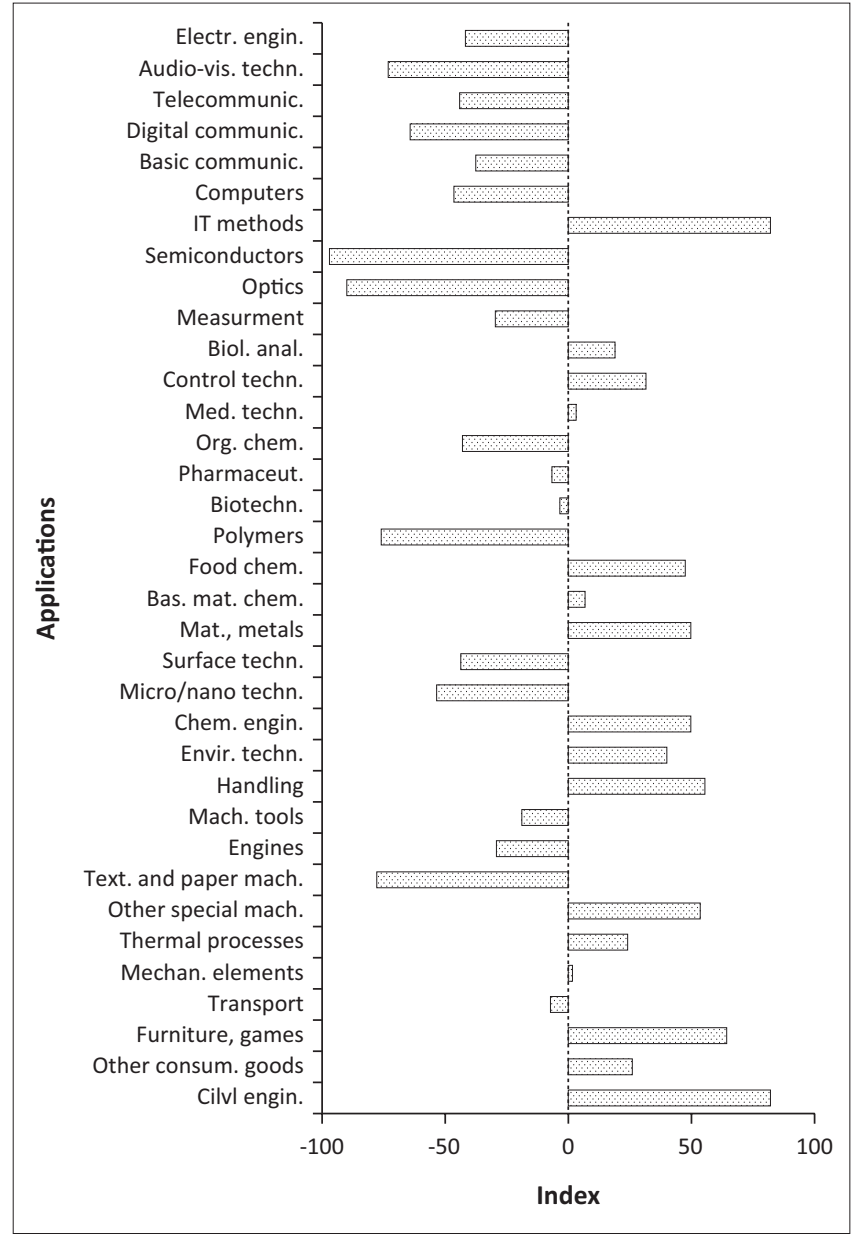

FIGURE 3: Specialisation profile of South African PCT applications, 2010-2018 (Reference: Worldwide transnational patents).

In mechanical engineering, positive specialisation can be found in handling, other special machines and thermal processes, but in the core fields of machine tools and engines, specialisation is below average.

In some research-intensive fields like biological analysis, or control, the specialisation is positive and in biotechnology, pharmaceuticals and transport at least average; but the total number of applications is quite low compared to other threshold countries. For example, in 2018 the total number of PCT applications in South Africa was 342, that in Brazil 874.

A reliable analysis of recent domestic applications in South Africa is not possible, as in the last four years, classifications in the majority of the domestic applications were not registered.

The specialisation profile of foreigners in South Africa is quite similar to that of the South African PCT applications. The main differences are the strong focus on biotechnology and pharmaceuticals, as well as the much higher number of applications compared to the domestic applications in South Africa. This means that foreign enterprises dominate the South African market by providing in similar fields as South African companies, through exports to, or production in
South Africa, but with higher intensity and more advanced products. From a certain critical distance, the South African patent system is primarily a competitive tool for foreign enterprises.

\section{Trade structures in South Africa}

Patent applications in foreign countries, in particular PCT applications, aim at the protection of exports. Therefore, it is interesting to see how the patent statistics are reflected in the export-import balance in South Africa. For this purpose, the World Integrated Trade Solution database (WITS) of the World Bank has been used as data source. In Figure 4 the situation is summarised and the dominance of raw materials illustrated; that is, diamonds, gold, platinum, etc. In fact, the exports of raw materials even increased between 2009 and 2018.

A positive trade balance can also be observed in intermediate goods. Intermediate goods are generally less complex elements of more complex products, assembled by a third party. For instance, the product group 'metals' comprises the production of steel products, which may be intermediate goods. Beverages, food, fuels and lubricants are intermediate goods as well. Food exports contribute to the positive balance of intermediate goods.

However, the trade balance in manufacturing, consumer goods and capital goods, is distinctly negative. There was a small improvement in time when consumer goods were less negative than capital goods. This reflects a South African technological specialisation in consumer goods (Figure 3) and a negative specialisation in production technologies (capital goods). The patents of foreign enterprises focus on consumer goods as well, with positive specialisation in production technologies. This technological dominance of foreign enterprises is reflected in the trade balance in manufacturing.

To improve the South African economy significantly, it is necessary to strengthen manufacturing. In more general terms, this can be labelled import substitution, an idea which became popular in the 1950s and 1960s, but was displaced by concepts of trade liberalisation. Recently, the idea of import substitution returned (Irvine 2020). In this context, South Africa's finance minister intends to set up manufacturing in order to make the products that we need and stop relying on imports from China (The Economist 2020).

\section{Technology and trade strategies in South Africa}

The suggested strategy for substituting imports implies a stronger focus on more sophisticated consumer goods and the establishment of our own structures for producing capital goods. This reorientation is linked to a stronger engagement in research and development (R\&D). However, in the last 10 years, the business expenditures on $R \& D$ in South Africa did, as a matter of fact, even decrease (Stats SA 2021). 


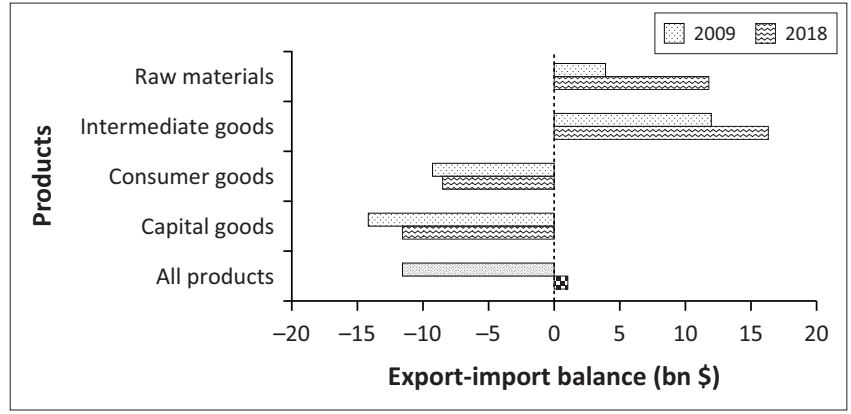

FIGURE 4: Export-import balance of South Africa for main product groups (in constant \$2018).

A further element in economic recovery is a stronger focus on the export of manufactured goods. According to this strategy, it is not realistic, regarding the limited resources for $R \& D$, to engage in many different technologies. As the international competition is fierce, it is only possible to become competitive at a high level of competency if the $R \& D$ activities are so focused as to achieve a sufficient critical mass. Therefore, it is recommendable to rather follow the Japanese strategy, which became a model to many Southeast Asian countries, such as South Korea, China, Taiwan and Singapore (Chang 2017; Kojimaa 2000; Utterback 1976).

In 1970, Japanese enterprises applied for only 105 patents in the USA, an even lower level than the present level in South Africa. At that stage, Japan focused on audio-visual technology, for example, small tape recorders or headphones. To achieve competitive solutions, the government cooperated with enterprises and research institutes. In 1980, Japan had 9925 patent applications in the USA with a clear focus on audio-visual technology. In the next step, the strategy was extended to computer technology, then to cars. In 2000, the number of Japanese patent applications in the USA reached 50 044, and Japan gained status as a fully industrialised country. To conclude, an initial focus on a small number of technologies, the coordination of $\mathrm{R} \& \mathrm{D}$ in enterprises with research institutes, and the gradual extension to other technologies, is a good strategy. With a sure focus on one technology, it is possible to achieve international competitiveness.

In the early years of this catch-up strategy, Japan financed the investment in R\&D by selling extremely cheap, simple consumer goods. In South Africa, this special support is not necessary as sufficient revenue is generated through the export of raw materials. Furthermore, there are already competitive scientific systems at South African universities and research institutes (research councils). So, the basic conditions for a stronger orientation toward $\mathrm{R} \& \mathrm{D}$ are good.

To achieve a stronger export orientation, it will be necessary to define possible fields of engagement in a process of discourse between government, enterprises, universities and research councils. It will be important, in particular, for industry associations to agree on targets in order to extend their product range to more sophisticated products.
Possible technologies for a stronger engagement were identified by the National Advisory Council on Innovation (NACI) in an elaborate process (DSI 2019). It suggested the following technologies: sustainable energy, health innovation, high-tech industrialisation, ICTs and smart systems, nutrition security, water security.

In the context of domestic and export activities, we want to illustrate the potential in high-tech industrialisation, ICTs, smart systems and water security.

The area of high-tech industries is typical for a stronger domestic engagement, as at present these technologies are imported from industrialised countries. For a higher level of independence, more competence in South African enterprises is necessary. In the NACI report the area is described as follows:

High-tech Industrialisation: Products, processes and services will be transformed through the application of smart and connected systems. The high-tech industry domain therefore focuses on the implementation of advanced manufacturing in South Africa using robotics, artificial intelligence, the Internet of Things and additive manufacturing, among others. This will transform old industries and give rise to new industries. Industry actors, including SMMEs ${ }^{1}$, will need to equip themselves with the necessary skills, infrastructure and capacity for a successful transition. (DSI 2019:25)

It will be difficult initially to achieve the same level as imported technology, for example, in robotics or additive manufacturing, but in a strategic step-by-step process, this could be realised. Good coordination between enterprises, government and research institutions is important. A detailed description of high tech industrialisation is found in DSI (2019:92ff.).

The South African competencies in ICTs and smart systems are already quite developed, as high specialisation in IT methods in patents is shown (Figure 3). The field is described as:

ICTs and Smart Systems: ICTs are one of the key enablers of development in all domains, from agriculture to health, and from industry to service delivery and governance. There are a number of technologies under the umbrella of ICTs. As recognised in the 2016 OECD $^{2}$ Science, Technology and Innovation Outlook, the Internet of Things promises a hyperconnected and ultra-digitally responsive society that supports human, societal and environmental development. Artificial intelligence offers unique opportunities to improve human lives and address major societal challenges. (DSI 2019:25)

Of course, there is strong competition from many countries, in particular the USA and China. But, there are diverse fields of application and niches could be found as entry points. This field is described in more detail in DSI (2019:100ff.).

\section{Another example is:}

Water Security: Water security as a basis for a thriving society and economy will depend on water and sanitation solutions that

1.Small and Medium Enterprises.

2.Organisation for Economic Cooperation and Development. 
are responsive to new challenges and emerging needs and opportunities. Three aspects are key to water security: (a) water supply will need to be driven by an integrated mix of contextappropriate sources of water at the bulk, regional and local level; (b) the next generation of sanitation and wastewater (urban and industrial) solutions will need to be introduced, understood and then mainstreamed (low or no water toilets, energy and waterefficient technology, and smart waste solutions); and (c) watersensitive designs for urban, peri-urban and rural spaces should be core to all water and sanitation planning and implementation (including grey water management, climate-resilient infrastructure, circular planning around water, and sanitation and wastewater flows). (DSI 2019:26)

In order to cope with water security a mix of technologies and management competencies are needed. South Africa could improve its water security, making it a thriving industry, perhaps we would be able to export our know-how to other countries. The relevant technologies and high-level services can be exported to industrialised countries (e.g. California, China), as well as developing ones. In any case, engagement in this area would benefit the situation in South Africa, as well as foreign trade. The field is described in more detail in DSI (2019:118ff.).

At universities, a stronger orientation towards applied research is important, especially in the context of the selected fields. In this way, relevant research results for enterprises, as well as qualified staff can be provided. At least one of the research councils should engage in applied research for viable enterprises, similar to the Research and Technology Organisations (RTO) in Europe which is described in more detail on the website https:/ / www.earto. eu/about-rtos/.

In terms of patents, the strategy for import substitution is primarily linked to more competitive domestic patent applications, compared to the patent applications of foreign enterprises in South Africa.

The strategy of exports in specific areas implies an increase in PCT applications in these technological fields and building up relevant patent portfolios in these areas.

\section{Conclusion}

The analysis of patent and trade structures in South Africa shows that targeting an increase in PCT patent applications should improve the country's economic situation. This target does not entail a simple increase in numbers, but must be linked to a coordinated technological strategy. From a midand long-term perspective on exports, this implies a focus on a small number of technologies in the beginning with a gradual extension.

A further relevant element in economic improvement is import substitution. This means more economies would be entering the trade balance with additional jobs in South Africa. In this context, an increase in the number of domestic patent applications is the main target.
To conclude, in the context of patents, an increase in the number of domestic and PCT applications is crucial. To this purpose, the electronic registration of patents in South Africa should be improved. This would facilitate statistical analysis. But it is more important that South African companies take note, in an easy and reliable way, in which areas their competitors are active.

\section{Acknowledgements Competing interests}

The authors declare that they have no financial or personal relationships that may have inappropriately influenced them in writing this research article.

\section{Authors' contributions}

U.S. and A.P. contributed equally to this article.

\section{Funding information}

This research received no specific grant from any funding agency in the public, commercial or not-for-profit sectors.

\section{Ethical considerations}

This article followed ethical standards for research without contact with human or animal subjects.

\section{Data availability}

The data used in this article, in particular the patent data, are publicly available. If necessary, the corresponding author can provide the data on reasonable demand.

\section{Disclaimer}

The views and opinions expressed in this article are those of the authors and do not necessarily reflect the official policy or position of any affiliated agency of the authors.

\section{References}

Boeing, P. \& Mueller,. E., 2015, Measuring patent quality in international comparison: Index development and application to China, ZEW Discussion Papers, No. 15-051, ZEW, Mannheim.

Chang, S.J., 2017, 'International expansion strategy of Japanese firms: Capability building through sequential entry', Academy of Management Journal 38(2). https://doi.org/10.5465/256685

Chen, Y. \& Puttitanun, T., 2005, 'Intellectual property rights and innovation in developing countries', Journal of Development Economics 78(2), 474-493. https:// doi.org/10.1016/j.jdeveco.2004.11.005

Department Science and Innovation SA (DSI), 2019, South Africa. Foresight exercise for science, technology and innovation 2030, NACl, Pretoria.

Frietsch. R. \& Schmoch, U., 2010, 'Transnational patents and international markets', Scientometrics 85, 185-200. https://doi.org/10.1007/s11192-009-0082-2.

Irvine, D.A., 2020, Import substitution is making an unwelcome comeback, PIIE Trade and Investment Policy Watch, July 8, 2020, viewed n.d., from https://www.piie. com/blogs/trade-and-investment-policy-watch/import-substitution-makingunwelcome-comeback.

Kojimaa, K., 2000, 'The "flying geese" model of Asian economic development: Origin, theoretical extensions, and regional policy implications', Journal of Asian Economics 11(4), 375-401. https://doi.org/10.1016/S1049-0078(00)00067-1.

Lundvall, B.A., Joseph, K.J., Chaminade, C. \& Vang, J. (eds.), 2011, Handbook of innovation systems and developing countries: Building domestic capabilities in a global setting, Edward Elgar, Cheltenham.

National Intellectual Property Management Office (NIPMO), 2019, Guideline 2.7, guidelines for the operation the Intellectual Property Fund, NIPMO, Pretoria. 
Pouris, A. \& Pouris, A., 2011, 'Patents and economic development in South Africa: Managing intellectual property rights', South African Journal of Animal Science 107(11/12). https://doi.org/10.4102/sajs.v107i11/12.355

Schmoch, U., 2008, Concept of a technology classification for country comparisons, Final Report to the World Intellectual Property Organisation (WIPO), WIPO, Geneva.

Statistics South Africa (Stats SA), 2021, South African National Survey of Research and Experimental Development, Statistical report 2017/18, 2019, Stats SA, Pretoria.
The Economist, 2020, 'How manufacturing might take off in Africa', The Economist, 13 June 2020 edition, viewed n.d., from https://www.economist.com/middle-eastand-africa/2020/06/11/how-manufacturing-might-take-off-in-africa.

Utterback, J.M., 1976, 'The process of innovation in five industries in Europe and Japan', in K. Stroetmann (ed.), Innovation, economic change and technology policies, proceedings of a seminar on technological innovation, pp. 251-265, Springer, Berlin. 